ISSN: 2172-9077

DOI: http://dx.doi.org/10.14201/fjc2016122740

\title{
LA RADIO EN EL OTRO LADO DEL TIEMPO
}

\section{Radio on the Other Side of Time}

\author{
Alicia TAPIA LÓPEZ \\ Profesora en ESIC Business \& Marketing School, España. \\ E-mail: alicia.tapia@esic.edu \\ (iD http://orcid.org/0000-0001-6764-0932
}

Fecha de recepción del artículo: 12/02/2016

Fecha de aceptación definitiva: 12/02/2016

\begin{abstract}
RESUMEN
El 30 de octubre de 1938, Orson Welles emitió la radionovela La Guerra de los Mundos en la CBS, adaptando una novela de ciencia ficción del escritor británico H. G. Wells. Esta dramatización sembró el terror de los oyentes cuando creyeron que en verdad la tierra estaba siendo invadida por marcianos con aspecto de serpiente gigante que disparaban rayos de fuego sobre los ciudadanos. Welles fue un pionero en crear trucos para explotar al máximo la nueva tecnología radiofónica, adaptando textos clásicos que ensalzaban la vanguardia del nuevo medio. A lo largo de los años se han llevado a cabo distintas adaptaciones de este clásico radiofónico, pero ninguna interpretación conforma los avances tecnológicos de nuestros días. Este artículo reúne la mayoría de las innovaciones de la radio de Internet imaginando su lugar en una emisión de la ficción de Orson Welles en la actualidad, donde la Red se ha convertido en soporte de emisión y los enlaces hipertextuales han facilitado la conexión entre distintos medios. El texto se adentra en el otro lado del tiempo, donde la narrativa transmediática propicia el intercambio de relatos entre los consumidores y la parrilla de programación rompe con la linealidad de su emisión.
\end{abstract}

Palabras clave: ciberradio; internet; narrativa transmediática; consumidor; telefonía móvil.

\begin{abstract}
On October 30, 1938, Orson Welles aired the radio drama The War of the Worlds on the CBS Radio network, adapting the science-fiction novel by the British writer H. G. Wells. During the broadcast, listeners became stricken with panic, believing that the Earth was actually being invaded by giant snake-like Martians launching rays of fire down on humans. Welles was a groundbreaking figure whose trickery exploited the technological novelty of the radio to its fullest, adapting classic texts in ways that exploited the opportunities afforded by this new medium. Over the years, this radio classic has been adapted a number of times, though none has seized on the technological advances of our times. Drawing on the most salient innovations seen in Internet radio, this article creates an imaginary scenario that replicates Orson Welles's work in the present day, when the Internet has become a channel for broadcasting and hyperlinks have brought different media together. The text is an exploration of the other side of time, where transmedia storytelling facilitates the exchange of stories among consumers, and broadcast programming is no longer linear.
\end{abstract}

Keywords: Internet radio; Transmedia storytelling; Consumer; Internet; Mobile phone. 


\section{INTRODUCCIÓN}

La emisión radiofónica de La Guerra de los Mundos despertó el pánico en Estados Unidos, al creer millones de oyentes que los marcianos estaban invadiendo nuestro planeta. El miedo de la conquista de la tierra por parte de extraterrestres despiadados con una tecnología desconocida provocó el pavor de los ciudadanos que corrieron atemorizados para huir de las ciudades. La aldea de Grover's Mill, en New Jersey, quedó totalmente arrasada por las bolas de fuego que lanzaron estos invasores de Marte tan altos como los rascacielos y con unos ojos negros de serpiente. El 30 de octubre de 1938, víspera de Halloween, Orson Welles emitió esta radionovela en la emisora del Columbia B. System (CBS), adaptando una novela de ciencia ficción de Herbert George Wells. En menos de 60 minutos, Welles provocó el terror en el país y eso que su equipo aclaró dos veces durante la retransmisión que se trataba de una dramatización. Esta adaptación radiofónica es un ejemplo clásico de la fuerza de la radio para crear sentimientos y emociones.

En la actualidad, si se escuchara este programa en directo, lo primero que haría el receptor sería buscar en su teléfono móvil un snap, un whatsapp o un tuit de un vecino de New Jersey para compartir en Instagram la foto de lo que estuviera ocurriendo. Los radioyentes acudirían tanto a la página web de la CBS como a la página de este medio en Facebook para informarse y contemplar alguna fotografía, realizada desde el Observatorio de Mount Jennings, en Chicago, "de las explosiones de gas incandescente que tuvieron lugar a intervalos regulares en el planeta Marte" (Koch, 1938, p. 2). Orson Welles habría creado un espacio en la Web y en las Redes Sociales sobre la invasión marciana, dedicando a alguno de sus guionistas a escribir como si fuera testigo de esta ficción. Su guerra entre mundos irrumpiría ineludiblemente en nuestro universo digital de este siglo XXI.

La entrada de la radio en Internet comenzó con la incorporación de datos sobre los programas y periodistas en las páginas web de las emisoras. Poco a poco el sonido analógico se convirtió en digital y las emisoras iniciaron el camino de mejorar los contenidos y la programación online. Pedrero, Sánchez y Pérez (2014, p. 2) destacan dos tipos de difusión de la radio digital. Por un lado, la radio digital terrestre, que transmite con la norma DAB (Digital Audio Broadcasting) mediante la TDT. Este tipo de difusión solo cuenta en España con 1\% de consumo por su elevado coste y porque no proporciona ninguna brecha creativa frente a la radio analógica. El otro tipo de difusión es a través de Internet. La radio digital en la Red se difunde mediante streaming y podcast. Tiene sus propias características y nuevos formatos de difusión:

Es necesario aprender a suministrar fragmentos de contenidos a los receptores, como mini entrevistas, declaraciones concretas, entresacadas de la programación del día a día, pero con tratamiento singular, que lo diferencie del resto de emisoras, para más tarde distribuirlo a través de Internet y el teléfono móvil. (Franquet, 2003, p. 152).

El desarrollo de Internet ha planteado una nueva forma de hacer radio, un nuevo entorno de comunicación, que requiere de la voluntad y el entusiasmo de los programadores, guionistas y periodistas para aprovechar todo su potencial:

Y el hecho que debe abordarse es que aún no se han encaminado los esfuerzos de las emisoras a mejorar la programación o los contenidos sino la tecnología (...) El esfuerzo creativo se ha rendido con facilidad ante el esfuerzo tecnológico. (García-González, 2010, p. 136). 
La radio ha cambiado y el consumidor también. La investigación sobre el consumo radiofónico realizada por López-Vidales y Gómez-Rubio (2014) a través del Observatorio de Ocio y Entretenimiento Digital (Ocendi) desvela, además de la preferencia de los jóvenes a escuchar la radio a través de los teléfonos móviles y otros dispositivos portables, que el joven espera de los programadores de radio una innovación de los contenidos y un desarrollo de otras formas de interactuar con el oyente.

En este nuevo espacio, Orson Welles tendría que contar con otros recursos y protagonistas que los utilizados en su invasión marciana ficticia de principios del siglo XX, y aun así le sería difícil crear el pánico real e histeria colectiva que provocó en las calles de New York y New Jersey, lugares donde se iniciaron los hechos según su radionovela.

\section{Metodología}

El objetivo principal de este artículo es verificar si las innovaciones tecnológicas de la radio online han evolucionado en paralelo a la creación de contenidos de calidad que definan el espíritu de una radio de vanguardia del siglo XXI.

En la primera fase de esta investigación se ha revisado la bibliografía actual sobre la nueva infraestructura radiofónica de Internet, su conexión con la Web 2.0 y su convergencia con la telefonía móvil y otros dispositivos. Los estudios de Pedrero, Sánchez, y Pérez (2014) sobre los retos de la industria radiofónica, de Cebrián (2009) y de Guitiérrez, Ribes y Monclús (2014) sobre la expansión de la ciberradio y la investigación doctoral sobre el podcasting de Gallego (2009) han aportado la base sobre las nuevas tecnologías de la radio de Internet. Muchos autores han coincidido en la exigencia de repensar las estrategias de la radio digital (Martínez, Moreno \& Amoedo, 2012), incluso han apostado por ceder espacio a los jóvenes prosumidores mediante la democratización del proceso comunicativo de la radio (López-Vidales y Gómez-Rubio, 2014).

El protagonismo del consumidor también ha sido objeto de esta investigación a través de las aportaciones de Jenkins (2003), Scolari (2013) y Herrero (2015) sobre la narrativa transmedia, una nueva forma de contar historias que en la ficción cuenta con la representación pionera de Pandemic 1.0, un cortometraje de diez minutos, producido por Lance Weiler y presentado en la edición 2011 del Sundance Film Festival, que incluye cincuenta mil fotos, más de un millón y medio de tuits, objetos que los usuarios tienen que describir, cien teléfonos móviles, etc. Asimismo se han explorado ejemplos revolucionarios en otras obras actuales y de antaño que han dejado huella en los relatos transmediáticos.

En una segunda fase de la investigación, se ha llevado a cabo un análisis del guion y grabación sonora de la radionovela original La Guerra de los Mundos (Welles y Koch, 1938), una obra maestra que simboliza la comunicación radiofónica de principios del siglo XX, cuya esencia consiste en provocar sentimientos mediante el sonido. Para alcanzar el objetivo de la investigación, se han analizado además las invenciones tecnológicas de las versiones radiofónicas más relevantes de La Guerra de los Mundos, como por ejemplo, la de Radio Quito, dirigida por Leonardo Páez en 1949, que incorporó como novedad las conexiones ficticias con otras emisoras cercanas advirtiendo del peligro de la invasión. La paradoja de esta ficción ecuatoriana se produjo cuando a mitad de programa la emisora fue incendiada por un grupo de oyentes encolerizados. Los periodistas no encontraron el auxilio de los bomberos y policías porque estos creyeron que las llamadas de ayuda formaban parte de la ficción.

En España, en 1995, Roberto Sánchez y su equipo emitieron en la cadena SER una dramatización sobre la red eléctrica de trenes, siguiendo la idea de Orson Welles de provocar el pánico a través de las 
ondas. Otra versión radiofónica destacada fue la realizada por Primitivo Rojas y Gregorio Parra (Radio 3) el 30 de octubre de 2008, en el Teatro Mira de Pozuelo de Alarcón de Madrid y bajo el patrocinio de la Academia de las Artes y las Ciencias Radiofónicas de España. En esta adaptación participaron la SER, Onda Cero, RNE, Cope, Punto Radio, Onda Madrid e Intereconomía, y se oyeron las voces emblemáticas de Luis del Olmo, Juan Ramón Lucas, Gorka Zumeta, entre otras. Esta fue una emisión fiel a la original, hasta los efectos especiales se realizaron en directo, pero en ningún instante existió una conexión entre los dos mundos, el del origen de la radio y el actual mundo online de la ciberradio.

Esta investigación parte de la hipótesis de que la radio de Internet cuenta con un desarrollo conveniente en infraestructura, pero con escasa evolución en la forma de hacer programas que generen sentimientos e informen, como la convencional, pero que también definan y describan el carácter e ingenio del consumidor de nuestro tiempo.

\section{LA GUERRA DE LOS MUNDOS EN UN CONTEXTO DIGITAL}

La radio digital puede emitir un programa íntegro en la Web mediante streaming. Con este sistema, la radio tradicional utiliza Internet como soporte de difusión y amplía su facultad de emisión en directo y en diferido. El streaming ha conseguido la emisión radiofónica mundial, beneficiando a muchos emigrantes españoles y permitiendo una difusión a 500 millones de hispanohablantes, pero el contenido sigue estando marcado por la radio analógica (Gallego, 2010, p. 171). En esta situación, la emisión de La Guerra de los Mundos habría llegado a muchos más oyentes que conectarían con el programa desde sus teléfonos móviles y en cualquier lugar del planeta. Habría creado una alarma global.

Otra característica de la radio en Internet es la emisión no lineal. El receptor online no escucha un programa de radio desde el principio, de forma lineal, hasta que acaba, sino que accede al contenido temático del programa en la web de la emisora. Debemos recordar que en Internet no existe tiempo de emisión sino acceso al contenido. Cobra importancia el espacio, las dimensiones de la pantalla, la forma de navegación (Martínez, Moreno \& Amoedo, 2012, p. 172). El programador virtual debe pensar en este espacio online como si fuera la parrilla de programación y actualizar los contenidos según el acceso de los consumidores. Por tanto la estructura de parrilla de la radio tradicional, que se caracteriza por la linealidad de la emisión y su estructura distribuida por horas y minutos, se transforma en una parrilla web, que mezcla programas íntegros con segmentos o cortes seleccionados temáticamente de otros programas en diferido. Un equilibrio entre la radio masificada, los contenidos especializados, los elementos multimedia, como la IPVoz, redes P2P y la RSS, y la importante incorporación del componente social colaborativo. Asimismo destacar nuevas formas de escucha radiofónica. El estudio de Guitiérrez, Ribes \& Monclús (2011, p. 314) señala que el 98,1\% de los jóvenes prefiere utilizar el teléfono móvil para escuchar la radio. Los autores distinguen además los resultados del informe británico Ofcom Communications Market Report ${ }^{1}$ que desvelan que, aunque los jóvenes consumen menos radio de antena convencional, son a su vez los que escuchan más contenidos de audio a través de teléfonos y otros dispositivos móviles (p. 307).

La emisión de La Guerra de los Mundos del siglo XXI alternaría el streaming del programa en directo con los podcasts de los fragmentos más relevantes y alarmantes, difundidos tanto en la Web de la emisora como distribuidos por redes sociales, como Twitter, Facebook y Reddit. Para una emisión en la actualidad, Welles y los programadores de la CBS tendrían que prever difundir por todo el universo digital primeramente los podcasts de la entrevista realizada al profesor Pierson del Observatorio de Princeton, interpretado por el mismísimo Wells, describiendo el fenómeno, como:

\footnotetext{
${ }^{1}$ Órgano independiente que regula las competencias de las industrias audiovisuales en el Reino Unido.
} 
Un chorro de llamaradas azules disparadas por un arma. (Koch, 1938, p. 2).

Y después, los podcast desgarradores y dramáticos del sonido del pánico de la gente corriendo por las calles de New York y las sirenas de los coches:

La policía y el ejército no logran controlar a la multitud. Se estima que por la mañana los fugitivos habrán duplicado la población de Filadelfia, Camden y Trenton. (Koch, 1938, p. 8).

La historia real del podcast se encuentra en la difusión de audio en streaming. La digitalización de los sistemas de producción de las emisoras de radio facilitó el corte, la selección no lineal y empaquetado de contenidos de un programa tanto en directo como en diferido. Y después la generación de radio a la carta, donde el oyente reclama su propia música, información y deporte. La radio a la carta permite al usuario una audición personalizada de los contenidos en directo y en diferido. Tras la radio a la carta, solo faltaba sumar al contenido el archivo RSS, que permite descargar de forma automática y desde el agregador la actualización de las descargas, sin tener que acceder a la web de la emisora. Esto es un podcast. El origen de la palabra Podcast parte de combinar las palabras iPod con Broadcasting (Gallego, 2009, p. 114).

Actualmente, la CBS cuenta con canales de podcast atractivos y el servicio Everyzing, que ofrece la posibilidad de encontrar palabras en los audios de la cadena. En el ámbito anglosajón destacar además a la $\mathrm{BBC}$, que sin duda alguna es un referente de radio digital a nivel mundial, y que dispone de un sistema de podcast desde el año 2004, un servicio de radio a la carta del iPlayer y también se puede escuchar los programas de la radio en streaming desde la web de la emisora.

$\mathrm{La} \mathrm{BBC}$ distingue entre tres tipos de contenidos de podcast.

- Emisiones íntegras de los programas.

- Resumen de los mejores momentos.

- Podcast temático de diferentes programas.

Gallego (2009, p. 238) señala como muy interesante el "podcast multiprograma a partir de una temática" porque es una forma de aprovechar los contenidos y de "fidelizar a los oyentes con intereses muy concretos".

En España, en abril de 2005, la cadena SER fue la primera en presentar contenidos podcast a sus oyentes. Años más tarde crearon contenidos diferentes a la emisión de la antena. Por ejemplo, el programa magazine Hoy por hoy cuenta con un podcast de 15 minutos con el resumen de lo más destacado del programa, con careta propia y publicidad.

Mención aparte los contenedores de radio online, también denominados audiokioskos, como Ivoox, que reúne podcasts y audios temáticos. Estos contenedores de audio son plataformas con un potente motor de búsqueda que recogen contenidos sonoros agregados de distintas cadenas y música (Gallego, p. 167). Por supuesto los podcast también se pueden escuchar desde la tienda de Apple iTunes Store. En 2009, La rosa de los vientos de Onda Cero fue líder de audiencia en el Top de podcast. Son un medio diferente a la radio. Mediante el podcast se llega a la negación del tiempo que ya expresaba Borges en sus Ficciones de 1941: 
El presente es indefinido; el futuro no tiene realidad sino como esperanza presente; el pasado no tiene realidad sino como recuerdo presente. (p. 21).

A su vez, un servicio podcasting es una forma de sistematizar los contenidos y una manera de personalizarlos. Gallego concluye su estudio, resaltando las escasas iniciativas de plataformas temáticas de contenidos de audio desligadas de las propias emisoras que existen en España.

Ante todo, la radio de principios del siglo XXI utiliza la Red como soporte de emisión, pero también adapta las ventajas de los enlaces del hipertexto y su fácil conexión con los distintos medios. Los últimos datos publicados por Infoadex (2016) destacan el 2015 como un año excelente para la radio. La inversión publicitaria en la radio aumenta con respecto al año 2014, de 420,2 millones de euros a 454,4 millones en el año 2015, superando en este año las extraordinarias cifras del año 2011 y 2012 , que registraron una inversión de 524,9 y 553,5, antes justo de su caída estrepitosa del año 2013 que no llegó a superar los 403,6 millones de euros en inversión publicitaria.

La radio en Internet ha ampliado y complementado las posibilidades expresivas del sonido para narrar la información diaria mediante un nuevo lenguaje multimedia, donde los audios, textos, fotografías, gráficos y vídeo se encuentran en un mismo relato y se distribuyen por diferentes canales de difusión (Martínez et al., 2012, p. 170). Además se ha instaurado una nueva narrativa, donde toma relevancia la hipertextualidad, la navegación y el intercambio de contenidos con otras fuentes y con los consumidores.

\section{DE LA FANTASÍA DE WELlES A LA NARRATIVA DE CORTÁZAR}

El concepto transmedia aparece por primera vez en el año 2003 en el artículo Transmedia Storytelling de Henry Jenkins, profesor de Comunicación, Periodismo y Artes Cinematográficas en la Universidad del Sur de California. Jenkins explica que en la narración transmediática, cada medio hace lo que mejor sabe hacer. De tal forma que una narración pueda ser incluida en un película, en una novela, en la televisión o en un cómic. Y describe al consumidor joven como un consumidor con una personalidad de cazador de información con un marcado carácter de conector de historias diferentes, algo frustrado porque los medios de comunicación no están preparados para "producir experiencias transmediáticas convincentes" mediante esa nueva infraestructura tecnológica que aguarda.

Actualmente, cualquier emisora de radio integra texto y fotografías como si fuera un nativo digital, marcando a través de la narración toda la trascendencia que caracteriza al periodismo digital, como la multimedialidad, la hipertextualidad, la interactividad y la actualización continua. Uno de los ejemplos más innovadores de reportaje multimedia es el llevado a cabo por el New York Times en el año 2012 con el proyecto Snow Fall, de John Branch, que narra la historia de unos esquiadores atrapados en las montañas del estado de Washington tras una avalancha de nieve. La narrativa multimedia utilizada integra fotografías, entrevistas de los protagonistas en vídeo e imágenes de la zona, a la vez que va avanzando el relato. Lo más impresionante de esta narración son las panorámicas virtuales de la zona montañosa conocida como Tunnel Creek, donde los esquiadores quedaron retenidos, y que los elementos multimedia forman parte constructiva de la propia narración.

Siguiendo este rasgo de multimedialidad, una emisión actual de La Guerra de los Mundos, innovadora como fue, tendría que convertir la página Web de la emisora CBS en una gran obra arquitectónica, donde el concepto de espacio y de entorno se refleje complejo y multidimensional. Cebrián destaca que la ciberradio es más que una web. Y que no debemos engañarnos incorporando chats, foros o 
correos. Es mucho más. También tiene que incluir los podcasting, los audioblogs y otras expresiones interactivas que la desarrollan para configurar una red comunicativa:

La ciberradio entra en un cibermundo en el que se modifican los tiempos y espacios reales por otros virtuales en los que adquieren otras dimensiones (...) La ciberradio se adentra en un universo global en el que se superan las fronteras físicas: local, regional, nacional e internacional de la radio tradicional para hacer hincapié en otras dimensiones de afinidad. (Cebrián, 2009, p. 14).

Alrededor de las ocho de la tarde, Orson Welles y su compañía teatral Mercury comenzó a interpretar desde los estudios de radio CBS de New York la adaptación de la novela del escritor británico H. G. Wells:

Sabemos que, en los primeros años del siglo veinte, este mundo era observado por inteligencias superiores a las del ser humano (...) Con infinita complacencia, la gente iba y venía por la tierra con sus asuntos, sintiéndose segura de su dominio sobre el fragmento rotatorio del sistema solar, que por azar, o designio, había heredado del insondable misterio del tiempo y espacio. (Koch, 1938, p. 1).

En nuestro presente, el guion de Howard Koch tendría que definir los contenidos internos, pero también los contenidos externos relacionados. Ahora, los oyentes de La Guerra de los Mundos habrían interactuado, conversando con la emisora y entre ellos. Contactado con algún oyente de Trenton, en New Jersey, para saber lo que estaba ocurriendo:

Cientos de automóviles se hallan estacionados en un terreno situado detrás nuestro. La policía trata desesperadamente de cercar con cuerdas el camino que lleva hacia la granja. Pero es en vano, la gente se amontona en desorden. Enormes reflectores arrojan una luz potentísima sobre el objeto semienterrado en la tierra. Algunos de los más osados tratan de acercarse; sus siluetas se reflejan sobre el fondo metálico. (Koch, 1938, p. 8).

Si el hecho fuera real, los consumidores creativos enviarían fotos y grabaciones de vídeo a través de sus teléfonos móviles mediante mensajería instantánea o conectando con las redes sociales. Por lo que Welles, poco a poco, podría ir dando forma al relato de ficción a través de narraciones transmediáticas (transmedia storytelling). La Guerra de los Mundos se distribuiría en una producción integrada en la ciberradio CBS, con el streaming del programa en directo, apoyada con vídeos publicados en la web y también en el canal de YouTube, siguiendo además otros parámetros para determinar un relato transmedia, como que los contenidos se difundieran en distintos dispositivos: portátiles, teléfonos móviles, tablets, etc. (Scolari, 2013). A continuación, Orson Welles redistribuiría los contenidos de su ficción por la Web 2.0, aprovechando la oportunidad de compartirlos a través de las redes sociales.

La radio de Internet se ha convertido en cauce de participación, aunque todavía su desarrollo no es significativo. En el caso de España, la primera cadena en utilizar Twitter fue Punto Radio, cuando en septiembre de 2009 crearon un microblogging para seguir en directo el programa Protagonistas, dirigido por Félix Madero, y recibir a su vez la opinión de los receptores. Por lo que se refiere a Facebook, el 
programa de Herrera en la Onda, presentado por Carlos Herrera en Onda Cero, fue el primero en iniciarse en esta red social a través de su comunidad de fans Los fosfonautas (Peña \& Pascual, 2013, p. 132). Pero las sinergias entre la radio convencional y las redes sociales cuentan con insuficientes estrategias de programación y un entorno interactivo todavía por desarrollar. Los programas radiofónicos publican en el muro de Facebook y en los tuits un discurso rígido y excesivamente planificado de antemano (Gutiérrez, Martí, Ferrer, Monclús y Ribes, 2014, p. 431).

Ahora bien, si nos asomamos de nuevo al otro lado del tiempo, cuando se emitió La Guerra de los Mundos, en el momento en que Borges escribió El jardín de senderos que se bifurcan, apreciamos que ya en aquella época existían autores que ideaban el relato transmediático; solo les faltaba la infraestructura tecnológica. Más adelante, en 1963, en plena madurez, Julio Cortázar escribió su original Rayuela, una novela con dos secciones. Una titulada, Del lado de allá, con capítulos que se leían de forma secuencial, y, la otra sección, De otros lados, que ofrecían una lectura desestructurada del relato a través de los capítulos elegidos por el lector. Cortázar tituló así su novela en referencia a este juego infantil, que consiste en dibujar un tejo de varias divisiones en el suelo e ir saltando, con un solo pie, a la pata coja, casilla a casilla hasta la última y con cuidado de no pisar las rayas. Como el juego de la rayuela es la parrilla de la radio y televisión convencional. Una rejilla de programación que sigue, paso a paso, una línea del tiempo y de las horas. Y unos programas que se emiten simultáneamente a todos los receptores. El programador selecciona los programas y planifica la parrilla de continuidad, cuidando sobre todo el horario de máxima audiencia, el prime time. Ese tiempo en el que toda la familia se sentaba en el salón junto a la radio y después frente al televisor para oír o ver su programa favorito, una radionovela, una buena película, etc.

En esta Era Digital, la emisión radiofónica de La Guerra de los Mundos seguiría la idea transmediática de Julio Cortázar. Una novela que se puede leer de forma convencional, lineal, un capítulo detrás del otro, del capítulo 1 al 56. Y que también proporciona otras formas de leer la novela, invitando al lector a que sea coautor, incluso creador. Hay un segundo nivel de lectura en la novela de Cortázar en relación a este juego de la rayuela: ir saltando de una manera, aparentemente desordenada, muy juguetona, muy lúdica, pero en el fondo se va siguiendo un tablero de indicaciones propuesto por el autor. Por ejemplo, hay capítulos que cuentan dos historias al mismo tiempo. Una historia se lee siguiendo los renglones impares y si uno lee los renglones pares, lee otra historia. En su forma y en su fondo, Rayuela reivindica la importancia del lector y le empuja hacia un protagonismo.

Un ejemplo sensacional de programa interactivo lo llevó a cabo Televisió de Catalunya el 21 de enero de 2007 con Guernica, pintura de guerra, primer documental interactivo español, coincidiendo con el 70 aniversario del ataque aéreo de la Legión Cóndor alemana durante la Guerra Civil Española y que inspiró a Pablo Picasso para pintar una de sus obras maestras. La Corporación Catalana de Medios Audiovisuales (CCRTV Interactiva) realizó tres interactivos del documental, que, a su vez, se podían consumir desde tres plataformas diferentes: Web, Media Center y TDT. Los usuarios podían navegar en la web por contenidos que explicaban la historia del cuadro, análisis del cuadro, entrevistas, biografías, juegos, visionar el documental e, incluso, se podían convertir en Tony Shafrazi ${ }^{2}$ y pintar sobre una imagen del cuadro permitiendo una "interacción generativa - contributiva" actúa como emisor y el responsable de contenidos del documental como filtrador o seleccionador de contenidos (Gifreu, 2013, p. 487).

\footnotetext{
${ }^{2}$ Nombre del graffitero que el 28 de febrero de 1974 escribió con un spray rojo Kill lies all (muerte a todas las mentiras) sobre el cuadro Guernica, que entonces se exhibía en el MoMa de New York, en protesta por la posición de EE. UU. en Vietnam.

3 Shafrazi experience. Modalidad de interacción generativa. Parte práctica de generación de dibujos y visualización en línea de contenidos ya creados a partir del mural Guernica de Pablo Picasso (Gifreu, 2013, p. 509).
} 
De la misma manera que la novela de Cortázar, el responsable de un programa de ficción tendrá que planificar un recorrido por cada uno de los canales y decidir cómo presentar y organizar los contenidos al receptor. En consecuencia su función es mostrar un gran catálogo audiovisual ante el público, en el que el tiempo ya no tiene relevancia, y gana importancia la diversidad, la seducción y la calidad de los contenidos.

\section{EL CONSUMIDOR COMO PROGRAMADOR Y CREADOR DE CONTENIDOS}

La radio y televisión de Internet se caracteriza por una audiencia individual, en vez de familiar. El receptor consume los programas en paralelo al resto de los usuarios, sin depender de su consumo o de la audiencia en general. Por tanto, la radio y la televisión online se transforma en emisor no lineal y, el público, en individuo. El programador planifica la parrilla de discontinuidad, por lo que es aconsejable producir nuevos esquemas de programas que provoquen la alinealidad en la recepción, como hizo Cortázar con su novela.

Es cierto que la participación del oyente en la radio hertziana se ha producido desde los inicios de este medio de comunicación a través del teléfono, por carta, discos dedicados, confidencias, etc. De hecho, en la ficción de Welles, el locutor conecta con el granjero testigo presencial de lo ocurrido, el policía, el profesor experto, y se oyen voces y gritos de terror de la multitud. Pero la radio de Internet va más allá porque ofrece la posibilidad de que los oyentes conversen entre ellos y la oportunidad de que los propios consumidores puedan producir sus propios contenidos.

La interactividad de Internet promueve el diálogo entre oyentes, siendo la propia audiencia la que decide cómo intervenir y la relación que mantiene con la emisora y con los otros oyentes. Esta interactividad entre los oyentes promueve la creación de comunidades temáticas en torno a un programa concreto o varios programas similares, como hemos destacado anteriormente con el grupo Los fosfonautas del programa de Carlos Herrera ${ }^{4}$. A su vez, las emisoras abren portales a foros, blogs, eventos, etc. La Guerra de los Mundos se convertiría en El jardín de senderos que se bifurcan, en un laberinto de laberintos donde...

... El tiempo es una red creciente y vertiginosa de tiempos divergentes, convergentes y paralelos. (Borges, 1941, p. 117).

Esa es la complejidad de una narración transmedia, que un mismo entorno informativo de ficción se expone en distintas plataformas que proporcionan diferentes relatos. Incluso a veces el autor del relato podría perder parte del control.

Asimismo la ficción de Welles del siglo XXI contaría con una página web específica donde los usuarios pudieran dejar sus mensajes y testimonios a través de la webcam. Acercándose de esta manera a la narración colectiva transmediática de algunas campañas publicitarias en línea, en lo que se denomina la pospublicidad, donde se mezclan los contenidos de la propia marca con la conversación de la gente, de las personas de la calle, que se convierten en autores. En el año 2009, Coca Cola puso en marcha en España la campaña de publicidad con el eslogan Destapa la felicidad mediante storytelling o narrativa transmedia. El spot de televisión, titulado Encuentro, narraba el viaje a Madrid de un abuelo mallorquín de 102 años para ver a su nieta recién nacida. Adicionalmente al spot, se incluyeron, por primera vez, unos mupis, donde los consumidores de siete de las ciudades más grandes de España pudieron fotografiarse y de esta forma su foto quedó expuesta en el cartel interactivo. Esta campaña publicitaria aportó además detalles de la vida real, como conexión a través de webcam desde los hospi-

${ }^{4}$ V.p. 6. 
tales, donde los padres de bebés recién nacidos narraban sus experiencias, $\mathrm{y}$, a su vez, los usuarios que accedían a esta campaña a través de la web construían la parte del relato que les interesaba y también podían aportar consejos para los nuevos padres. Esta campaña culmina con la creación por parte de Coca Cola del Instituto de la Felicidad (Herrero, 2015, p. 3).

Desde luego constituye una nueva forma de narración, donde cada fragmento de texto o de audio aporta significado al relato global y contenido a distintas historias que el consumidor puede unir en un mismo universo digital. Herrero destaca que el éxito de esta campaña publicitaria fue que se publicó en la Web. Fue entonces cuando el consumidor, maravillado por los relatos, los fragmentó y compartió, transformándose en storyteller, en un propagador de relatos.

Esta facultad de asociar contenidos sonoros abre la posibilidad de que el oyente empaquete de nuevo los contenidos seleccionados según sus criterios, creando una programación a su medida. A continuación, los usuarios de Internet han desarrollado el periodismo ciudadano a través de los blogs y se han acostumbrado a producir sus propios contenidos y a ser emisores de información, posibilidad que antes solo estaba en manos de unos pocos.

Por otra parte, con la radio a la carta, el oyente se convierte en programador de sus contenidos, según su tiempo de escucha. Ahora mediante el podcast, el oyente se transforma de programador a generador de contenidos sonoros que difunde de forma masiva por la Red. Gallego (2009, p. 199) señala que el podcast ha engendrado una audiencia que escucha programas de radio fuera del perímetro de las emisoras tradicionales en Internet. La otra cara de la moneda son los oyentes que han decidido generar contenidos y pasar de receptores a emisores y, a veces incluso, a protagonistas.

Al otro lado del paisaje mediático, el espectador sigue consumiendo los programas en modo off li$n e$, a través de la radio y televisión tradicional, pero además utiliza otros dispositivos que le permite ser programador de su propia parrilla. Las emisoras de radio y televisión han comenzado a ocupar el espacio de las nuevas tecnologías, volcándose especialmente en la Red y en la telefonía móvil. El informe de la Fundación Telefónica (2015, p. 34) indica que en 2014 el teléfono móvil ha sido el dispositivo favorito de los consumidores españoles para acceder a Internet en movilidad, 4 millones más que en 2013.

Para que esto sea posible es necesario el desarrollo de aplicaciones (app) que permitan interactuar con los programas de la radio inteligente y la telefonía móvil de tercera generación. Asimismo, el perfeccionamiento de estas aplicaciones ha establecido claras diferencias en la estructura de los programas y canales difundidos en movilidad. Estas apps proporcionan una usabilidad más amigable, intuitiva y eficiente para los programas que se difunden por teléfono móvil, por lo que surge una divergencia entre los programas emitidos a través de la web y los difundidos mediante apps en móviles y tablets.

En el caso de una emisión actual de La Guerra de los Mundos, el programa contaría con su propia app para que el usuario de telefonía móvil escuchara la radionovela desde cualquier lugar en streaming y también pudiera seleccionar los podcasts más inquietantes. Tras la eliminación del periodista que relataba la invasión marciana desde la azotea del edificio de la CBS y una vez interrumpida la conexión, el profesor Pierson, que interpretaba Orson Welles, se mantenía escondido en medio de la devastación extraterrestre. Será entonces cuando la app enviaría mensajes intermitentes de Richard Pierson a los oyentes, haciéndoles creer que conformaban el directo de lo sucedido:

He permanecido oculto en esta casa vacía cerca de Grover's Mill... una pequeña isla de luz, perdida entre el negro humo que oscurece el mundo. Todo cuanto ha ocurrido antes de la llegada de estos monstruos a la tie- 
rra, me parece ya parte de otra vida... una vida que no tiene conexión con la actual... (Koch, 1938, p. 22).

A continuación la aplicación estaría preparada para recibir comentarios de los consumidores en tiempo real y conversar con Pierson y con otros supervivientes ficticios, sin que en ningún momento los usuarios supieran que se encontraban envueltos en un juego de realidad alternativa ${ }^{5}$.

Igual de importante en el estudio de la convergencia multimedia es el Second Screen de televisión. Los aparatos móviles, como iPads, iPhones, smartphones, tablets, ordenadores, etc., se han transformado en segunda pantalla de televisión, con unas funciones de participación e interactividad muy altas. Antena 3 y Televisión Española han sido las pioneras en ofrecer un servicio de segunda pantalla con Ant 3.06 y Más Isabel, en el año 2012 (Barrientos, 2013, p. 359). Básicamente, las aplicaciones desarrolladas para esta segunda pantalla permiten mayor participación del espectador. Pueden ofrecer desde imágenes exclusivas de la serie, más información, curiosidades, perfil de los personajes, etc. Y a su vez el espectador puede conectar con otros usuarios y conversar mediante el hashtag de la serie. Por ejemplo, una misma emisión puede producir diferentes contenidos, como vídeos avance, preguntas relacionadas con el argumento, informaciones que animen al espectador a dar su opinión, etc.

Igualmente se ha destacado que este consumo conectado es más individual. De tal manera que extrae al espectador del grupo familiar para transportarle a interactuar con la audiencia del programa a través de las redes sociales, chats y foros. Un $21,7 \%$ de consumidores conecta a menudo con la audiencia de un programa concreto a través de redes sociales. Esta interacción se puede llevar a cabo durante el visionado de la serie o programa en directo, tras descargarlo en diferido o en cualquier otra situación (Diego et al., 2014, p. 185).

En 2009, la cadena norteamericana CNN fue pionera en emitir un acto en directo a través de las redes sociales, al incorporar la primera investidura de Barak Obama a Facebook. El espectador pudo ver en directo la toma de posesión del presidente norteamericano y conversar con otros internautas sobre el acto.

Es evidente que la convergencia tecnológica ha despejado la pasividad del receptor, brindándole distintos procedimientos de participación. El espectador pierde el contacto próximo y gana en conexión permanente, aunque lejana, y se convierte en productor y difusor de contenidos audiovisuales. El receptor se transforma en productor amateur cuando reproduce o distorsiona documentos audiovisuales, creando nuevos productos que difunde a través de las redes sociales a grupos afines. Es una nueva modalidad de consumo basada en la democratización de la creación de la obra audiovisual. Es conocida con el nombre de webcasting y YouTube y Facebook representan el ejemplo predominante de plataformas de intercambio de los nuevos consumidores - productores.

\section{CONCLUSIONES}

Sin duda alguna, YouTube es la plataforma principal donde los usuarios suben sus propios contenidos audiovisuales para compartirlos con el resto de cibernautas. No existe un programador sino que todos los clips se combinan de forma horizontal. No hay parrilla, pero los creadores de los vídeos han etiquetado sus contenidos a través de folksonomías que permiten al usuario recuperarlos cuando lo desee. Por tanto el usuario de YouTube se ha convertido en creador, programador y emisor de contenidos, aceptando de esta manera el convite de la tecnología a participar en el proceso audiovisual. En

\footnotetext{
${ }^{5}$ El primer juego considerado como JRA fue el diseñado para la película de Steven Spielberg, Inteligencia Artificial, de 2001.

${ }^{6}$ Un breve apartado para destacar que con esta denominación de 3.0 quieren distinguir el futuro, lo nuevo. En ningún momento se intenta vincular con la esencia 3.0 y la Web Semántica (Jodar, Polo \& Jiménez, 2010, p. 253).
}

(C) Ediciones Universidad de Salamanca / CC BY - NC ND $\quad$ Fonseca, Journal of Communication, n. 12, 2016, pp. 27-40 
este siglo, La Guerra de los Mundos albergaría diferentes tiempos y uno solo. Orson Welles tendría que prever diferentes escenarios de un laberinto, que los propios consumidores, ya sean prosumidores o storytellers, convertirían en un laberinto infinito, en donde esta fantasía radiofónica se reprodujera y recreara mediante un mashup, por ejemplo, donde la mezcla de relatos termine creando un punto de vista diferente o cualquier otro modelo de content curation:

El pasado infinito nos penetra y se desvanece. Solo que, dentro de él, en algún sitio, como diamantes, existen fragmentos que se niegan a consumirse. Cribándolos, si uno se atreve, y recopilándolos, se descubre el dibujo verdadero. (Vila-Matas, El País, 22 de abril de 2014).

La base de la comunicación sonora ya no es el soporte. Ahora el contenido es la esencia y, en este sentido, la emisora de radio se convierte en marca, en creador y programador. En la recepción se encuentra un oyente que selecciona contenidos y los comparte con otros usuarios.

Esta interactividad es una de las singularidades de la radio y televisión de principios del siglo XXI. Contamos con la posibilidad de privacidad para escuchar y ver nuestros programas favoritos, pero a su vez disfrutamos de una comunicación global con los consumidores de esos programas y con la propia cadena que los emite (Barrientos, 2013, p. 380). De igual importancia es la mutación de este consumidor, que, aprovechando los recursos de la web, ha modificado su actitud pasiva y se ha integrado de forma colaborativa, creando sus propios contenidos y concibiendo nuevos géneros que merecen nuestra atención.

El resultado del estudio realizado por López-Vidales y Gómez-Rubio (2014) sobre el consumo de la radio entre los jóvenes españoles revela una radio austera, con otros competidores muy fuertes en radio musical, como YouTube y Spotify. Por tanto la radio temática musical y la radio online en general precisa una evolución que la diferencie, renovando su programación e incorporando formas para que el consumidor, ahora activo, participe en el proceso comunicativo.

En este siglo XXI, quizá La Guerra de los Mundos no habría sido tan creíble porque los storytellers, prosumidores, y, en conjunto, todos los consumidores colaborativos, habrían desvelado la ficción de Welles a golpe de un click. Esta ficción describía la radio tradicional. Una radio que no podía escenificar la narrativa revoltosa y enredada que adivinaron Cortázar y Borges antes de tiempo, cuando la tecnología no les facilitaba su representación. Welles utilizó con ilusión las ondas hertzianas para crear una obra radiofónica espectacular. Borges fue premonitorio de la red de redes en sus Ficciones y Cortázar se apartó de la linealidad de la novela clásica para ofrecer al lector una mayor libertad receptiva.

Mediante el recuerdo de la ficción de Orson Welles, se ha analizado la diferencia entre la radio convencional y la radio online, que a su vez comienza a distinguirse según la escuchemos en la web o en los teléfonos móviles y tablets. La programación de la radio de Internet no debe ir solo encaminada hacia la convergencia sino también proporcionar un diseño mucho más fantástico e imaginativo. Es imprescindible tener en cuenta los esfuerzos colaborativos de los consumidores, asimilar las tendencias que se manifiestan en Internet y aprovechar la infraestructura tecnológica. Lo esencial es llegar al equilibrio entre los dos lados del tiempo e inventar una ciberradio en la que el usuario participativo y el consumidor pasivo se encuentren en un determinado punto. 


\section{BIBLIOGRAFÍA}

Barrientos-Bueno, M. (2013). La segunda pantalla televisiva: la aplicación Ant 3.0 de Antena 3. Icono 14 Revista de Comunicación y Nuevas Tecnologias, 11(2), 357-383. doi: 10.7195/ri14.v11i2.568

Borges, J.L. (1944). Ficciones. Buenos Aires: Emencé Editores.

Cebrián, M. (2009). Expansión de la ciberradio. Enl@ce Revista Venezolana de Información, Tecnología y Conocimiento, 6(1), 11-23.

Cortázar, J. (1963). Rayuela. Buenos Aires: Pantheon Books.

Diego-González, P., Guerrero-Pérez, E. \& Etayo-Pérez, C. (2014). Televisión conectada en España: contenidos, pantallas y hábitos de visionado. Mediterránea de Comunicación, 5(1), 179-199. doi: 10.14198/MEDCOM2014.5.1.10

Ellis, J. (2000). Scheduling: the last creative act in television? Media, Culture and Society, 22, 25-38. Recuperado de http://mcs.sagepub.com/content/22/1/25.short

Franquet, R. (2003). La radio ante la digitalización: renovarse en la incertidumbre. En E. Bustamante (ed.), Hacia un nuevo sistema mundial de comunicación: industrias culturales en la era digital (pp. 139160). Barcelona: Gedisa.

Fundación Telefónica. (2015). Informe Sociedad de la Información en España 2014. Barcelona: Ariel. Recuperado de http://www.fundaciontelefonica.com/arte_cultura/sociedad-de-lainformacion/informe-sociedad-de-la-informacion-en-espana-2014/

Gallego, I. (2009). Podcasting. Nuevos modelos de distribución para los contenidos sonoros. Barcelona: Universidad Oberta de Catalunya (UOC).

García-González, A. (2010). Radio digital e interactiva. Formatos y prácticas sociales. Icono 14, 15, $133-$ 146. doi: $10.7195 /$ ri14.v8i1.285

Gifreu, A. (2013). El documental interactivo como nuevo género audiovisual (Tesis Doctoral, Universitat Pompeu Fabra).

Recuperada de http://agifreu.com/interactive documentary/TesisArnauGifreu2012.pdf

Gutiérrez, M., Ribes, M. \& Monclús, B. (2011). La audiencia juvenil y el acceso a la radio musical de antena convencional a través de Internet. Comunicación y Sociedad, 24(2), 305-331. Recuperado en

\section{http://hdl.handle.net/10171/27349}

Gutiérrez, M., Martí, J. M., Ferrer, I., Monclús, B. \& Ribes, X. (2014). Los programas radiofónicos españoles de prime time en Facebook y Twitter: Sinergias entre la radio convencional y las redes sociales. Revista Latina de Comunicación Social, 69, 418-434. doi: 10.4185/RLCS-2014-1018.

Herrero, E. (2015). El storytelling y la narración transmediáticas. Revista Telos (Cuadernos de Comunicación e Innovación), 102, 1-5. Recuperado en

https://telos.fundaciontelefonica.com/DYC/TELOS/LTIMONMERO/DetalleArtculo 102TELOS EXPERIENCIAS/seccion=1288\&idioma=es ES\&id=2015110316550001\&activo=6.do\#

InfoAdex. (2016). Estudios Info Adex de la Inversión Publicitaria en España 2015. Madrid: Infoadex.

Jenkins, H. (15 de enero 2003). Transmedia Storytelling. MIT Technology Review. Recuperado de http://www.technologyreview.com/news/401760/transmedia-storytelling/

Jodar-Marín, J. Á., Polo-Serrano, D., \& Jiménez-Marín, G. (2010). ¿Dónde quedó el 2.0? El falso concepto de la televisión 3.0. Icono 14 Revista de Comunicación y Nuevas Tecnologías, 8(3), 251-264. doi: $10.7195 /$ ri14.v8i3.239

Koch, Howard. (1938). Guion de La Guerra de los Mundos. MLCSadrid: Academia de las Artes y las Ciencias Radiofónicas de España. Traducción de Jorge Álvarez. 
López-Vidales, N. \& Gómez-Rubio, L. (2014). La democratización del proceso comunicativo en radio: los jóvenes prosumidores. Revista de Comunicación Vivat Academia, 126, 31-53. doi: 10.15178/va.2014.126.31-53

López-Vidales, N. \& Gómez-Rubio, L. (2014). Nuevos hábitos de los jóvenes españoles y tendencias de futuro en el consumo de radio y televisión. Historia y Comunicación Social, 19, 327-340. doi: 10.5209/rev.HICS.2014.v19.45031

Martínez-Costa, M. P., Moreno, E. \& Amoedo, A. (2012). La radio generalista en la red: un nuevo modelo para la radio tradicional. Anagramas, 20, 165-180. Recuperado en http://www.scielo.org.co/scielo.php?script $=$ sci arttext\&pid $=S 1692$ 25222012000100012\&lng=es\&nrm=iso\&tlng $=$ es

Peña, P. \& Pascual, A. (2013). Redes sociales en la radio española. Facebook, Twitter y Community Management. Zer, 35(18), 123-144.

Recuperado en http://www.ehu.eus/ojs/index.php/Zer/issue/view/889/show'Toc

Pedrero, L., Sánchez, C. \& Pérez, A. (2014). Desafíos de la industria radiofónica española en el entorno digital: hacia la redefinición de su modelo de producción, comercialización y difusión. En XV Foro Universitario de investigación en Comunicación, Universidad de Vigo, Galicia. Recuperada en http://www.foro2014.com/wp-content/uploads/2014/02/33.-PedreroEsteban S\%C3\%A1nchez-Serrano-P\%C3\%A9rez-Ma\%C3\%ADllo.pdf

Scolari, Carlos A. (2013). Narrativas Transmedia: cuando todos los medios cuentan. Barcelona: Deusto Ediciones.

Vila-Matas, E. (22 de abril 2014). Las citas descolocadas, El País. Recuperado de: http://cultura.elpais.com/cultura/2014/04/21/actualidad/1398105568 677221.html 